Portland State University

PDXScholar

10-17-1978

\title{
Effects of Cognition Training on Locus of Control (LC), Weight Reduction, and Problem Solving Ability
}

Lisa Buckmaster

Portland State University

Follow this and additional works at: https://pdxscholar.library.pdx.edu/open_access_etds

Part of the Cognitive Psychology Commons, and the Health Psychology Commons Let us know how access to this document benefits you.

Recommended Citation

Buckmaster, Lisa, "Effects of Cognition Training on Locus of Control (LC), Weight Reduction, and Problem Solving Ability" (1978). Dissertations and Theses. Paper 2856.

https://doi.org/10.15760/etd.2850

This Thesis is brought to you for free and open access. It has been accepted for inclusion in Dissertations and Theses by an authorized administrator of PDXScholar. Please contact us if we can make this document more accessible: pdxscholar@pdx.edu. 
AN ABSTRACT OF THE THESIS OF Lisa Palumbo Buckmaster for the Master of Science in Psychology presented October 17, 1978.

Title: Effects of Cognition Training on Locus of Control, Weight Reduction, and Problem Solving Ability.

APPROVED BY MEMBERS OF THE THESIS COMMITTEE:

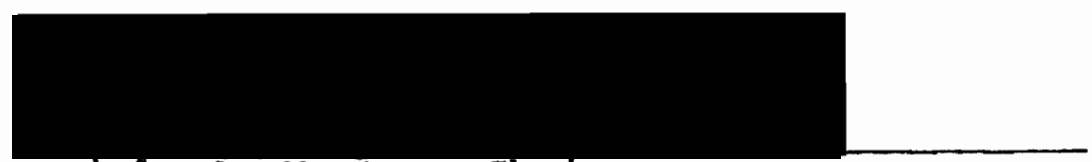

Pamela 0. Munter, Chairperson
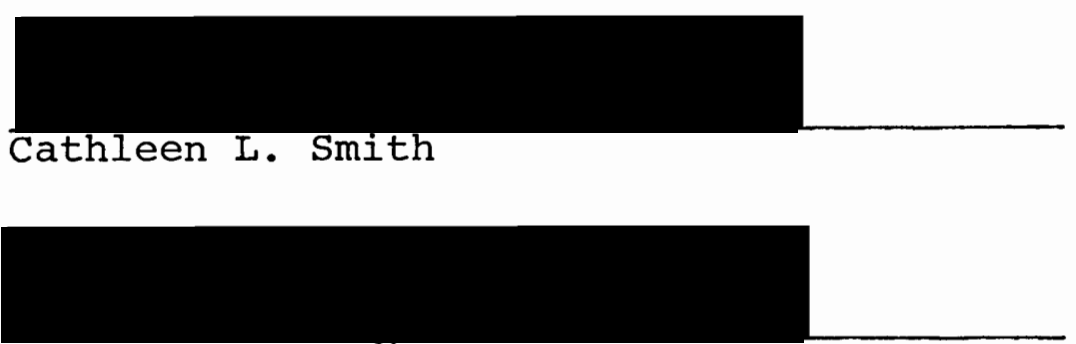

Barbara J. Stgrart

Weight control is an area of research which continues to generate attention in an endeavor to find the most effective and long lasting weight loss methods. In the realm of the behavioral modification of weight control, emphasis has been given to the impact of external stimuli on eating behavior. Less well researched are internal stimuli, that is, cognitive events, feelings, and thoughts which influence eating habits. The literature on obesity 
has yet to empirically differentiate the effects of the cognitive and external factors on weight control. A cognitive restructuring approach to weight reduction was hypothesized to be the more effective treatment when compared to a strictly external self-modification weight control program. The Cognitive Restructuring group received training in cognitive intervention techniques such as, rehearsal, covert sensitization, relaxation, cognitive countering, recording of moods, and covert imagery, in addition to skills in external cue control. The external group was designed to maximize the incorporation of external cues in a weight control paradigm. The two treatment methods were compared with a control group. Each treatment group and control group consisted of six subjects.

All subjects were measured on three variables: 1) weight, 2) the locus of control scale, and 3) the meansends problem solving device. The average weight reduction for the Cognitive Restructuring group was 8.29 pounds with a standard deviation of 5.20 pounds. The mean weight loss for the External Control treatment group was 6.0 pounds with a standard deviation of 7.77 pounds. The control group receiving no treatment demonstrated a gain of 2.33 pounds. Although the Cognitive Restructuring group lost 2.29 pounds more than the External Control group, this difference was not statistically significant. Both 
treatment groups indicated a significantly greater weight loss than the control group. On the means-ends problem solving device, only the Cognitive Restructuring group demonstrated significant increase in ability to generate appropriate solutions to a given goal. Additionally, a significant shift toward internalization, that is, a belief of personal control over one's environment, occurred only in the Cognitive Restructuring group. From these conclusions, the preferred treatment modality was the CRT based on the data that an increasing number of effective cognitive techniques enhanced personal attribution of weight control behavior.

A follow-up study is planned to evaluate the longterm differences between the two treatment groups in their ability to maintain their weight loss. 
EFFECTS OF COGNITION TRAINING ON LOCUS OF CONTROL (LC), WEIGHT REDUCTION, AND PROBLEM SOLVING ABILITY

by

IISA BUCKMASTER

A thesis submitted in partial fulfillment of the requirements for the degree of

\author{
MASTER OF SCIENCE \\ in \\ PSYCHOLOGY
}

Portland State University

1978 
TO THE OFFICE OF GRADUATE STUDIES AND RESEARCH:

The members of the Committee approve the thesis of Lisa Palumbo Buckmaster presented October 17, 1978.

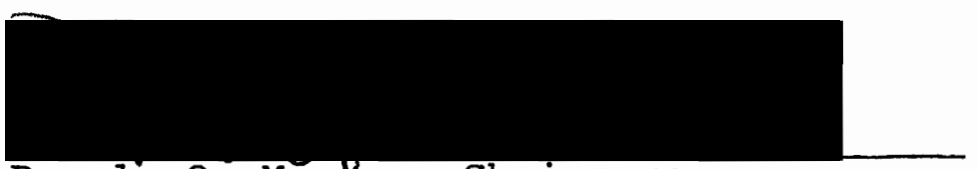

Pamela 0. Munter, Chairperson

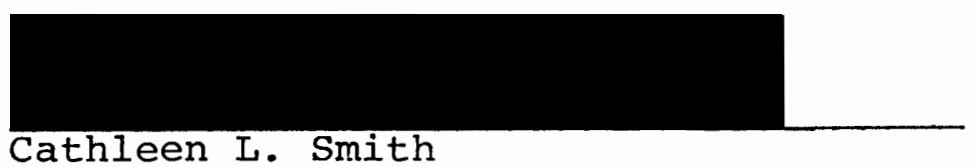

Cathleen L. Smith

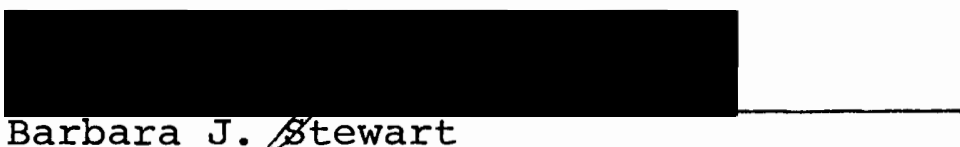

APPROVED :
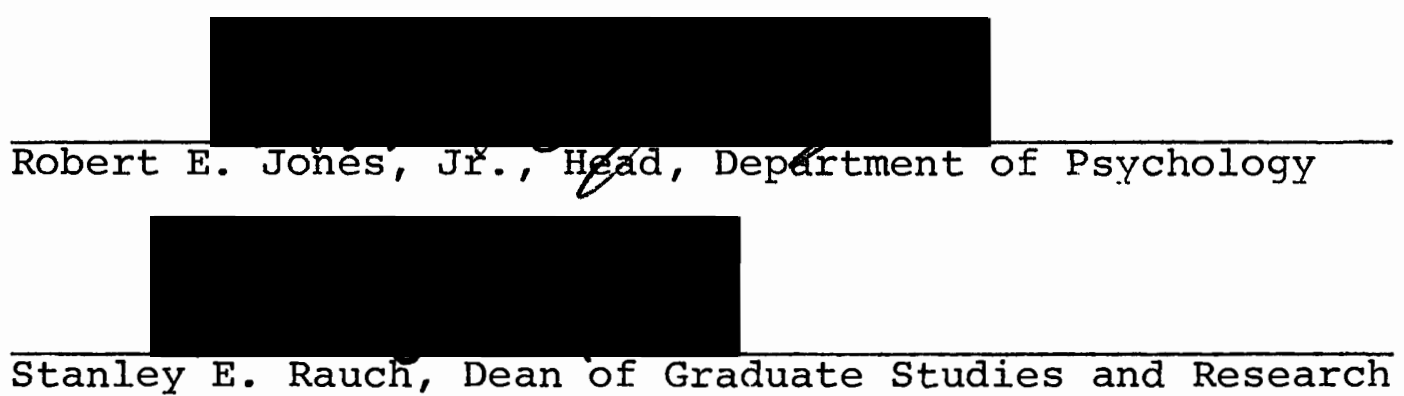
TABLE OF CONTENTS

Page

LIST OF TABLES . . . . . . . . . . . . . . . . iv

INTRODUCTION . . . . . . . . . . . . . . . I

METHODS . . . . . . . . . . . . . . . 18

Subjects . . . . . . . . . . . . . 18

Procedure . . . . . . . . . . . . . 19

The Cognitive Restructuring Training

Procedure ............. 21

The External Control (EC) Group Procedure . . 24

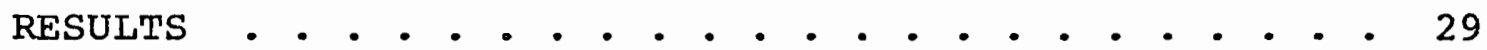

Weight Loss . . . . . . . . . . . . . 29

Loss of Control . . . . . . . . . . 30

Means-Ends Problem Solving Ability . . . . . 31

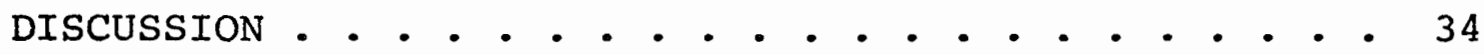

Findings for the CRT Group . . . . . . . . 35

Findings for the EC Group . . . . . . . . 36

CRT and Success in Therapy . . . . . . . . 37

Anecdotal Findings and the Future of CRT in

Weight Control............ 38

BIBLIOGRAPHY . . . ... . . . . . . . . 41

APPENDICES . . . . . . . . . . . . . . . . 44 45

Appendix A: Informed Consent . . . . . . 45

Appendix B: Locus of Control . . . . . . . 47

Appendix C: Means-Ends Stories....... . 51

Appendix D: Daily Food Intake . . . . . . 55

Appendix E: Tables . . . . . . . . . . 57 


\section{LIST OF TABLES}

Table

$\underline{\text { Page }}$

I Treatment Schedules . . . . . . . . . . 27

II Cognitive Restructuring Subjects' Weight Change in Pounds . . . . . . . . 58

II External Control Subjects' Weight Change In Pounds . . . . . . . . . . 59

IV Control Subjects' Weight Changes in Pounds . 60

$V$ Analysis of Variance Summary Table of Weight Change ............ . 61

VI Analysis of Variance Summary Table, Locus of Control: Pre-Treatment Scores . . . . 62

VII Pre-Treatment and Post-Treatment Scores on Locus of Control . . . . . . . . 63

VIII Analysis of Variance Summary Table, MEPS Pre-Treatment . . . . . . . . 65

IX MEPS Pre-Treatment and Post-Treatment Scores . . . . . . . . . . 66 


\section{INTRODUCTION}

Weight control is an area of research which continues to generate attention in an endeavor to find the most effective and long lasting weight loss methods. The most highly publicized and possibly the most reliable treatment found for effective weight loss has been the behavior modification technique of external stimulus control and self-recording of foods ingested (Stuart and Davis, 1972). The bulk of the literature concerning this technique focuses on attempts to effect weight loss by modifying external stimuli, that is, cues outside the cognitive sphere of the individual that are physically or temporally present.

The problem of defining internal and external stimuli has not been resolved in research studies. External factors, for purposes of this study, include physiological hunger, taste, time variability of eating, presence and amount of food, social situations, etc. Less well researched are the internal stimuli (cognition, or cognitive events, feelings, thoughts) that influence eating behaviors. Until recently internal stimuli were not widely recognized in the behavioral school of psychology, since such perceptions, thoughts, cognitions, and beliefs were considered too subjective and difficult to quantify. The concept of response chains helps delineate 
external and internal dimensions of behavior. A stimulus $\left(S_{1}\right)$ leads to a response $\left(R_{1}\right)$. This response may in turn become the discriminative stimulus $\left(\mathrm{S}_{2}\right)$ for an additional response $\left(R_{2}\right)$. The following diagram will aid in illustrating the chaining principle (from Ferguson, 1975). As the diagram indicates, the chain may continue as responses and stimuli alternate between cognitive (e.g., feeling bored, feeling sleepy) and external (e.g., watching a lousy TV show) dimensions.

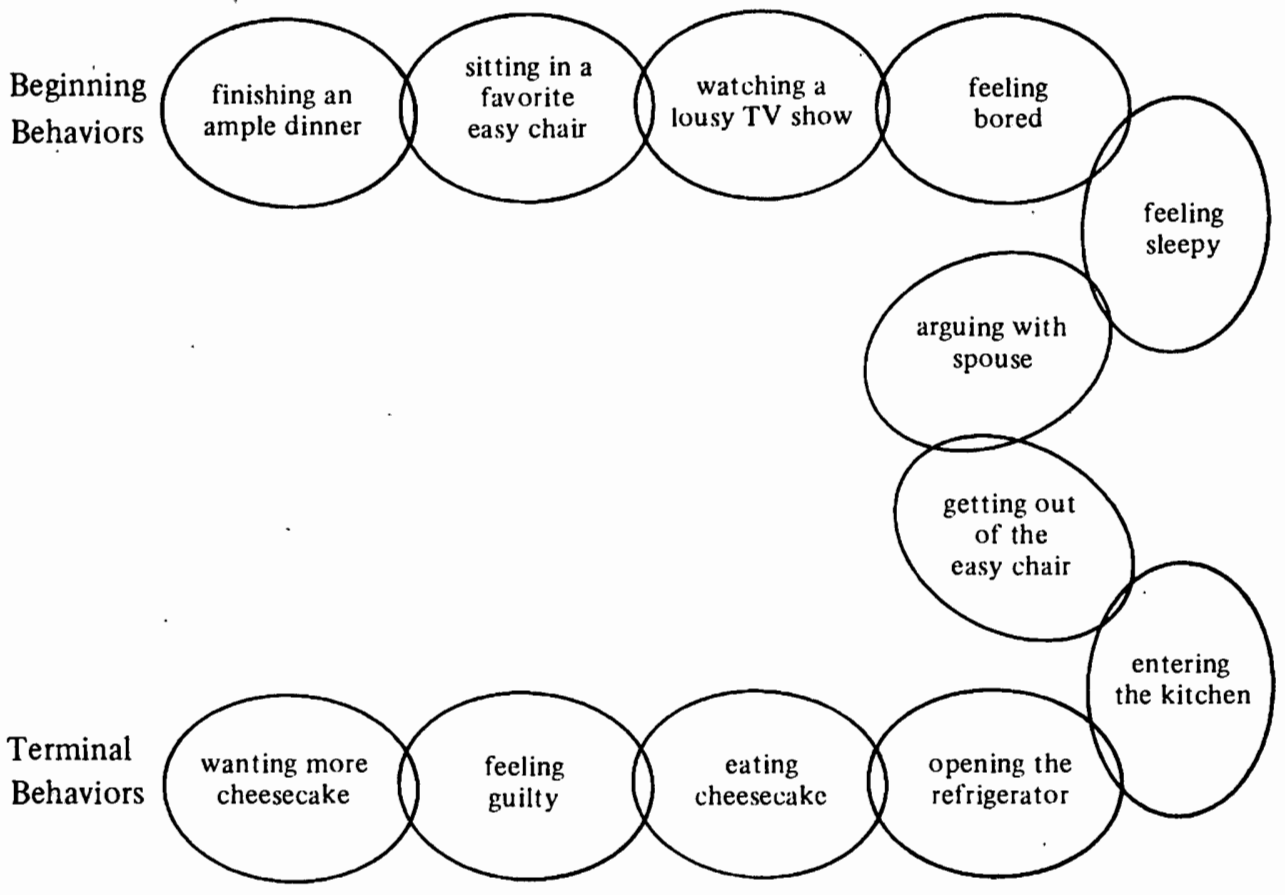

The works of Mahoney (1974), Meichenbaum (1974), Bandura (1969), Kanfer (1970), and Ellis (1962) have shown the importance of cognitive influences that go beyond external environmental events. To analyze aspects of behavior, 
both cognitive and environmental factors are thought to be important.

The cognitive processes that influence behavior have been discussed by Mahoney (1974) and Bandura (1969), and include attention, mediation, and motivational or incentive conditions.

Attention, which can be directed toward internal or external events, refers to a selective condition in which different individuals attend to diverse stimuii given the same environment. Attentiveness to different events accounts in part for differences in behavior. For example, individuals at a cocktail party attend to different stimuli associated with the party. One person may be attracted to a member of the opposite sex. Another may attend to foods and beverages. Yet another may experience feelings of social inadequacy. Knowledge of stimuli to which an individual attends aids in the explanation of behavior and is useful in treatment plans for therapeutic intervention.

Mediation refers to those processes that account for coding or cognitive representation of events on which attention has been focused (Mahoney, 1974). The process of mediation influences behavior in that material to which one attends is stored in memory. To effect behavior change, it is helpful to ensure that learned material has been coded and processed. Imaginal or verbal rehearsal facilitates retention of learned material (Bandura, 1971). In such a 
rehearsal the individual codes the model's behavior, i.e., describes verbally to oneself what the model did. Mediational phenomena, such as anticipation of outcome, expectations, and misperceptions may be related to maladaptive behavior (Rotter, 1954). In the obese person, negative misperceptions of eating perpetuate maladaptive behavior. For example, it is not uncommon to find an obese person who feels like a failure for having eaten 2000 calories in one day. Rather than objectively realizing that she/he could eat one hundred calories less each day for the next week, she/he catastrophizes that she/he is a failure, and indulges in binge eating. The concurrent thought is often, "What is the use, I will always be fat."

Motivational or incentive conditions are more than the actual consequences of behavior. Cognitively, focus is given to an individual's thoughts and perceptions of the consequences. If consequences of behavior are imaginally presented closer in proximity to the behavior, the cognitive representation of consequences may determine the next behavior. For example, if every time a person stood in front of the refrigerator and imagined himself ten pounds heavier, he might choose not to open the refrigerator door. The above components of cognitive behavior may provide avenues of intervention that result in observable behavioral change, i.e., manipulation of covert events may be used to mediate behavior change. In relation to weight 
control it is necessary to ascertain whether additional variability may be statistically accounted for by cognitive behavior change or whether controlling external stimuli is sufficient in sustaining weight loss.

Below is a brief review of studies that deal with internal dimensions of stimuli and their effect on addictive behavior. In an effort to effect overt change in weight control, it is of interest to explore covert behavior of individuals. With extensive Iiterature demonstrating that obese subjects are significantly more affected by external stimuli than normal weight subjects (e.g., Stuart and Davis, 1972; Schachter, 1971; Nisbett, 1968), it is logical to ask whether the cognitive processes of obese vs. non-obese differ.

In terms of cognitive behavior, coverant control has received much attention. Homme (1965) has developed the concept of "coverant" (covert operant) in an attempt to incorporate covert responses into the framework of selfreinforcement research. The coverant is defined as a response class consisting mainly of cognitive and imaginal behaviors (e.g., thoughts and images).

Recent work of Cautela (1970a, b) and others has emphasized the potential role of cognitive responses in therapeutic behavior change. Covert target behaviors have typically involved thought disorders, self-evaluative statements (Mahoney, 1971), or cognitive antecedents of an overt 
response pattern (McFall, 1970). Homme's (1965) paper on coverant control formed a foundation for empirically based attempts at modification of cognitive response.

In 1971 Horan and Johnson designated 96 obese women into four treatment groups: reinforced coverants, scheduled coverants, information and encouragement, or delayed treatment control. Subjects of the first two groups practiced negative/positive coverant pairs subvocally (e.g., "obesity is ugly," "if I lose weight my body will be firm"). subjects in the reinforced coverants group followed their subvocalization with a high frequency behavior such as sitting in a particular chair. In the scheduled coverant group, individuals were told to repeat the coverant pairs to themselves at least seven times per day. After eight weeks subjects in the reinforced coverant group lost 5.66 pounds, compared with mean losses of $2.72,3.13$, and 0.02 in the scheduled coverants, information and control groups respectively.

Horan et al. (1974) compared the effects of positive vs. negative coverants. Positive coverants were reported to produce significantly greater weight loss than negative coverants.

Covert reinforcement is a procedure whereby an individual pairs an imaginal performance and an imaginal reinforcer (Cautela, 1970). The use of covert responses as symbolic consequences was applied in counter conditioning 
paradigms. Affectively pleasant or unpleasant images were associated in systematized networks of responses (Mahoney, 1974). In a series of covert conditioning experiments, Cautela (1970a) has examined the effects of imagined events on preceding behavior. Results indicate that covert conditioning techniques may be promising, although findings are sometimes ambiguous. Cautela labeled a covert aversion procedure "covert sensitization." After relaxation training, an obese subject was asked to imagine the following scene (Mahoney, 1974).

I want you to imagine you've just had your main meal and you are about to eat your dessert, which is apple pie. As you are about to reach for the fork, you get a funny feeling in the pit of your stomach. You start to feel queasy, nauseous and sick all over. As you touch the fork, you can feel some food particles inching up your throat. You're just about to vomit. As you put your fork into the pie, the food comes up into your mouth. You try to keep your mouth closed because you are afraid that you'll spit the food out all over the place. You bring the piece of pie to your mouth: As you're about to open your mouth, you puke; you vomit all over your hands, the fork, over the pie. It goes all over the table, over the other people's food. Your eyes are watering. Snot mucus is all over your mouth and nose. Your hands feel sticky. There is an awful mess. As you look at this mess you just can't help but vomit again and again until just watery stuff is coming out. Everybody is looking at you with a shocked expression. You turn away from the food and immediately start to feel better. You run out of the room, and as you run out, you feel better and better. You wash and clean yourself up and it feels wonderful (Cautela, 1967, p. 462).

The above procedure was effective in producing a 66 pound weight reduction which was maintained over seven months. This impressive study led to the attempt of Manno 
and Marston (1972) to isolate the contribution of covert sensitization to weight loss. Their study compared a control group, covert sensitization, and covert reinforcement. Both covert conditioning therapies resulted in significantly greater weight loss and maintenance of weight loss.

Covert reinforcement can be either negative or positive in nature. The following sample typifies positive covert reinforcement.

Now let's work on the examination situation. It is the day of the examination and you feel confident. ("Reinforcement.") You are entering the building in which the exam is going to be given. ("Reinforcement.") You remember that in all these scenes you are to try to feel confident. Now you enter the building and go into the classroom. ("Reinforcement.") You sit down and kid around with another student who is taking the exam. You feel good; you know you are ready. ("Reinforcement.") The proctor hands out the exam. ("Reinforcement.") You read the questions and you can answer all of them. ("Reinforcement.")

Now let's do that again. This time you look the questions over and you are not too sure about one question, but you say, "Oh well, I can still pass the exam if I flunk this one question." ("Reinforcement.") All right, this time you look over the exam, and you can see two questions about which you are in doubt, and you say, "Well, I can still pass this exam if I take my time and relax." ("Reinforcement.") (1970b, p. 39).

Not all studies have demonstrated that covert sensitization is effective (Wilson, 1974). Contradictory finds suggest unspecified factors in treatments and varying populations. It is not yet clear that covert sensitization, by itself, is an overall effective treatment modality for weight loss. 
In further exploration of cognitive behavior control Premack (1971) maintained that habitual, non-premeditated target behaviors should first be returned to a status wherein thoughts consistently precede their emission. This forced mediation increases the distinction between the stimulus and response which provides an additional opportunity for interrupting the behavioral chain. Mischel (1973) supported the concept and elaborated that the imposed interruption of the response sequence may facilitate self-control attempts.

One of the basic impediments which discourages experimental analysis of coverant control is the reliance upon the subject as a response detector and contingency manager. The coverant is observable only to the person directly experiencing it; therefore, there is no direct means to monitor its frequency or manipulate its effects. An indirect verbal or nonverbal report provides a measure of coverant behavior that requires only that the individual be able to indicate its presence or absence.

One technique might be illustrated by an individual passing a sign of a local delicatessen and getting the urge to eat. He would then emit a covert response incompatible with his desire to eat, e.g., "My pants are getting tighter." A positive covert response consistent with not eating would then be emitted, e.g., "I'll feel so good if I don't have a bloated stomach." Finally, the 
individual would reinforce himself for mediating the behavioral chain. The reinforcer could be covert ("You are employing your new eating behaviors well and really have control") or tangible (he rewards himself with a night at the movies).

Another method used in research employs arbitrary cues as aids to self-mediated behavior change. An example of this would be the use of a piece of adhesive tape over the face of one's watch as a discriminative cue for the emission and subsequent reinforcement of some class of coverant (Mahoney and Mahoney, 1976). Each time the tape was visible, the subject was instructed to review his thought for the preceding minute. He then listed those thoughts into constructive and maladaptive lists. Inappropriate thoughts are countered with constructive cognitions, and the subject rewards himself.

Two other methods of mental intervention are provided in Mahoney and Mahoney's text. One involves making a mental movie in which the individual is the performer, critic, director, and star. The subject pictures himself performing new behaviors. This imaginal rehearsal is to be as detailed as possible to illustrate vividly to the individual what cognitive association he might have given a particular situation. The goal of such an exercise is to elicit thoughts and feelings one is likely to encounter in the actual situation. Mental rehearsals serve as a way 
to modify goals without having actually performed the future behavior.

The second technique involves the individual playing his/her own therapist. The subject is to pretend that his/her best friend has come for advice and help regarding the exact problem of the subject. The question that is asked in this procedure is "Would I set this goal for another person who has my problem and personal history?" Such cognitive therapy rehearsal aids the individual in appropriate cognitive exertions and alleviates selfdeprecating monologues.

The above cognitive interventions hopefully perpetuate a self-control concept on the part of the subject which enhances an individual's ability to sustain weight loss. However, few assessment devices are available to measure change in 'cognitive components of behavior. For purposes of this study, two measures of cognitive behavior will be explored.

One potentially useful cognitive variable in weight, reduction programs is the concept of locus of control (LC). LC is a continuous measure of how much an individual perceives his life to be controlled by external forces, such as fate and politics, vs. his/her actions and choices. One study suggested that obese vs. non-obese do not differ significantly on scales of internal-external locus of control (Geller, Keane, and Scheirer, 1977). In this 
study of 24 obese subjects and 24 non-obese subjects, no difference was found between the groups on internalexternal locus of control scores. However, Balch and Ross (1975) found a significant correlation between internalexternal scores in both completion of weight reduction group sessions and successful weight loss. Internal scoring subjects attended meetings at a significantly higher rate and were more successful in weight loss (i.e., they lost at least the median weight loss of all subjects) than their external counterparts. This offers speculation that if one's locus of control can be shifted toward a more internal locus via cognitive training and external stimulus control, one would be more successful in weight reduction. This is in line with the theory that a person who believes that he is the cause of his own behavior is more likely to maintain his behavior in the absence of external rewards (De Charms, 1968).

Previous research has shown that success in therapy is related to client's perceived ability to control external events, internalization (Pierce, 1970). G. S. Felton and B. E. Biggs (1972) found a significant difference between pre-program and post-program locus of control scores, in the direction of internality, for experimental subjects as a group. In their study they attempted to teach internality to collegiate low achievers. Three techniques were used to effect change in locus of 
control scores. First, orientation to present time encouraged individuals to choose among currently available alternative behaviors. The subject acknowledged responsibility for his/her choice, including a decision not to act. Second, confrontation directly imposed on the individual the consequences of his/her interpersonal behavior. In order not to avoid responsibility, it was necessary to publicly choose an immediate response, including inaction. Third, the language of responsibility was used to express feelings. Substitution such as the personal "I" instead of a distancing "it," "you," or "one" was encouraged. Instead of allowing "I can't," only "I won't" was deemed admissible. "Why," "because," "try" were all discouraged as such words focus on past and future, and attention is directed away from the participant.

D. B. Jeffrey (1974) compared the effects of external control and self-control on the modification and maintenance of weight reduction. He defined selfreinforcement as the process of the individual dispensing reinforcers to him/herself, while external reinforcement was considered to be dispensed by someone other than the individual (e.g., therapist). Sixty-two subjects were divided into three treatment groups: (1) external control with nonrefundable contingency, (2) self-control with refundable contingency, and (3) a self-control group with nonrefundable contingency. His results indicated that all 
three treatments were equally effective in producing reduction in weight. However, both self-control treatments were more effective than the external group in long term maintenance of the reduction. Results are in line with De Charms's (1968) theory that cognitive training may serve as a promoter to expedite self-control and long term behavior change.

An obvious adjunct of perceived locus of control in cognitive mediation is the concept of interpersonal problem solving in relation to addictive behavior. Problem solving has been defined as:

a behavioral process, whether overt or cognitive in nature, which (a) makes available a variety of potentially effective response alternatives for dealing with the problematic situation and (b) increases the probability of selecting the most effective response from among those various alternatives (D'Zurilla and Goldfried, 1971, p. 108).

Although the terms above are ambiguous and necessitate a formal operational definition, "procedural specification and operationalized performance measures have facilitated an apparently adequate exchange of communication," (Mahoney, 1974). D'Zurilla and Goldfried (1971) suggest the procedural components of problem solving include five basic stages:

1. the generation of a problem solving "set" or orientation

2. definition of the problem

3. generation of alternative solutions

4. tentative selection of a solution

5. testing of that solution (verification) 
Several studies of Jerome J. Platt suggest that, when compared to their normal counterparts, persons who demonstrate cognitive deficiency with regard to solving typical real-life, primarily interpersonal problems engage more often in maladaptive behaviors (Platt et al., 1971). Platt and Spivack (1971) examined the problem-solving abilities of psychiatric patients and found that when compared with non-patient controls, patients were less capable of addressing themselves to hypothetical real-life problematic situations, and were also less capable of providing intermediate steps which would result in the solution of the problem. Similar findings were obtained for impulsive teenagers in a residential setting when they were compared with normal middle class adolescents (Spivack and Spotts, 1967). Problem solving cognition, a dimension to describe the ability to think adaptively, has not been applied in research in obese subjects, but has received attention in another addictive behavior, drug abuse (Platt, Scura, Hannon, 1973). This study found significant differences, as measured by the Means-Ends Problem Solving Device (MEPS), between incarcerated heroin addicts and non-addict controls.

It is hypothesized in this study that in maladaptive eating, a cognitive blocking occurs which effectively impedes problem solving directed toward weight control. Therefore, a psychological dysfunction is indicated in the 
obese subject who is unable to cope effectively with the demands placed by problematic overt or covert stimulus situations. Cognitive blocking should be eliminated through problem solving therapy and replaced with more productive approaches to the presenting problem of impulsive eating.

Sheerer (1963), Davis (1966, 1973), and Gagne (1964) have reviewed extensive literature in the domain of problem solving. A detailed discussion of the problem solving literature would not be appropriate for the purposes of this study. However, the hypothesis is that with increased interpersonal problem solving ability, (1) weight reduction maintenance is more likely to occur, and (2) locus of control is more likely to shift internally.

A test for problem solving ability has been developed called the Means-Ends Problem Solving Device (MEPS). This test has been shown to be statistically independent of measures of intelligence, creativity, and academic advancement (Platt et al., 1971). The MEPS instrument measures the extent to which an individual is capable of conceptualizing effective and appropriate means of reaching a solution when presented with problem situations involving an aroused need.

From the foregoing information several important questions arise that deserve empirical attention. First, it is necessary to find whether adding several cognitive 
training procedures to mediate covert (and consequently overt) change in eating behavior produces significant improvements in weight reduction and maintenance of weight loss. Next, further experimentation needs to be offered to establish what changes, if any, occur in locus of control due to different types of therapeutic intervention. Finally, the issue of group differences in problem solving ability should be examined. Obese vs. non-obese subjects should be compared, as well as subjects trained solely in external stimulus control vs. subjects trained in both internal and external stimulus control. In order to quantify and test the impact of the cognitive environment, it is necessary to use a design that isolates the cognitive components of behavior from the external stimuli. This study will do part of the above by attempting to test the following hypotheses:

1. Cognitive training is significantly more effective than external treatment and no-treatment as reflected by changes in locus of control (LC), MEPS, and weight reduction. Pre-treatment and posttreatment scores on these measures will be compared.

2. External training is significantly more effective than no treatment as reflected by locus of control, MEPS gains, and weight reduction. 


\section{METHODS}

\section{Subjects}

Subjects of this study were initially solicited through advertisement in the Women's Resource Center monthly newsletter in Vancouver, Washington, which was distributed to various agencies in the community. The subjects called in to the Women's Resource Center to register for the class, and were randomly assigned to the treatment and control groups. Those in the control group were placed on a waiting list and given the explanation that the class was full. If they provided pre-treatment data they would also be eligible for the same treatment program ten weeks later.

of the 41 women responding, 31 met the following criteria: 1) At least $10 \%$ over medically desirable weight (as defined in Hershman, 1977); 2) Willing to participate in a weight loss program for 10 consecutive weeks; 3) Not pregnant; 4) Not involved in any other current weight loss program; 5) Not on any medication which might affect weight loss, such as "diet pills." The 31 subjects were divided into two experimental treatment groups and one control group. 
$\underline{\text { Procedure }}$

Experimental Treatment Group one received cognitive restructuring training (CRT) in addition to learning methods to manipulate one's external environment such that it is conducive to weight loss. Group Two concentrated only on methods pertinent to external environmental control of eating behaviors (EC), and was not schooled in cognitive restructuring training. Group Three received no treatment whatsoever, and served as a control for changes which might have naturally occurred over time as a result of expressed interest in weight control.

In the first meeting, all of the subjects completed the following: 1) informed consent form; 2) Means-End Problem Solving Stories (see Appendix); 3) the Locus of Control Inventory; 4) a weight chart indicating their current weight, height, and wrist measurement to ascertain the size of the frame. In addition the experimenter provided Food Intake Forms for each subject to fill out daily until the next meeting (see Appendix). The food intake forms asked for the following information: type of food eaten; amount; place; time; with whom; antecedent, concomitant, and consequential behaviors to eating, and caloric value. Group one (CRT) additionally indicated their mood while they ate, whereas for Group Two (EC, external control) no attention was given to mood, feelings, or cognitions. A discussion regarding the 
outline of the next nine weeks ensued, and the meeting ended.

The second group meeting focused on reviewing research demonstrating Pavolvian principles of paired stimuli relative to obesity and eating patterns. It was explained that baseline procedures, that is, food intake forms, aid in pinpointing paired stimuli that create maladaptive eating behaviors. Nutrition information was presented and a 1200 calorie diet was recommended.

The reasoning behind implementing a 1200 calorie diet is that the nutritive requirements for the average woman are not met at an intake level below this amount of calories. In order to calculate the number of calories necessary and nutritively sufficient to lose one pound per week for a woman with an average frame, the following equation is utilized. The ideal weight is determined by allowing 100 pounds for a woman five feet tall and adding five pounds per inch over five feet. That weight is converted to kilograms and multiplied by twenty calories to provide the number of calories consumed to lose one pound per week (Hershman, 1977).

$\frac{100+5 \text { (\# in. over } 5 \mathrm{ft.})}{2.2} \times 20$ calories $=\begin{aligned} & \text { maximum } \\ & \text { calories to } \\ & 1 \text { lb. per week }\end{aligned}$ If the frame size of the woman is smaller or larger than average, as determined by wrist size, ten per cent of the 
calculated maximum calories to lose one pound per week is deducted or added, respectively, to that number. From this point on the regimen of the two experimental groups departed from each other. (See Table I, p. 27, for treatment schedules of the experimental groups.)

The Cognitive Restructuring Training Procedure (CRT)

The CRT group met $1-1 / 2$ hours per week and followed this schedule:

In week three, relaxation training was instituted by using a 40 minute, 16 muscle group relaxation tape. Subjects were taught to use relaxation as a substitute for eating that occurred at times of fatigue, anxiety, and/or stress. Food intake format was reviewed to preclude inaccurate recording of eating behavior. To continue on the Pavlovian principle taught one week earlier, subjects were asked to initiate five cue elimination techniques throughout the next week. These included: 1) Eat in a designated appropriate eating place; 2) When eating, only eat; 3) Remove food from all places in the house, office, and car except from appropriate storage areas such as the kitchen; 4) Have healthful, lower calorie foods visibly available. Throw away particularly troublesome foods; 5) Do not keep. serving containers on the table while eating.

Week four was used as a review of stimulus control techniques and awareness of cues that exacerbate 
inappropriate eating patterns. Subjects were also advised to give attention to putting their forks down between bites of food and thoroughly chewing and swallowing their food before picking up the utensil for their next bite. In addition, they were to closely monitor moods in conjunction with eating for the next week.

Throughout weeks five and six specific concentration was given to behavioral chains, especially mood related chained events. The subjects were asked to compose a list of seven enjoyable activities and three necessary activities which would substitute for eating contingent upon mood, such as boredom, anxiety, anger, etc. A ratio was to be recorded of the number of bites taken with the fork placed down to the total number of bites in a five minute segment of a meal. Subjects were also taught to reward themselves for good eating habits, rather than weight loss.

The seventh week entailed training in positive covert imagery. Subjects role played and modeled situations that they could mentally rehearse to yield appropriate weight control behaviors. Such imagèry could take on any positive reward on a cognitive level to the subject. For example, one subject used the fantasy of her own body in perfect muscular form running in front of her to serve as an incentive to increase her own running behavior. The concept of pre-planning one meal per day 
was presented as an exercise to enhance a cognitive set toward expected and actual eating behavior. Pre-planning has a dual function of serving also as an external cue to appropriate eating .

Lesson eight centered around additional sources of cue elimination in one's external environment to reduce impulse eating. Subjects were instructed to 1) use smaller plates, 2) not eat everything on their plate, 3) divide portions of food in half and return for "seconds" only if hungry, 4) throw away leftover food unless it was part of the pre-planned menu for the next day, 5) not accept offers of food, but take responsibility and ask for the food, and 6) minimize contact with food by putting away all food preparations before sitting down to eat. The CRT group then practiced using superficial cues to review their own cognitions about eating over periods of time. For example, pieces of tape would be placed in conspicuous locations to remind the subject to review thoughts pertaining to weight control. A list of negative and positive cognitions was kept, and subjects were taught how to counter negative thought patterns and reinforce positive images.

Lesson nine paid particular attention to energy expenditure as a necessary factor in a weight control paradigm. Subjects listed the positive and negative aspects of exercise, and special attention was given to 
irrational or defeatist perceptions of exercise. Enjoyable forms of exercise were added as a substitute activity when hunger pangs occurred. Subjects were asked to purchase a pedometer and take a baseline of their current activity level. Daily energy expenditure was to increase 50 calories each subsequent week until 250 calories were expended per day. The remainder of this meeting reviewed problem solving techniques already learned by the subjects, that is, finding multiple solutions to eating problems. A "brainstorming" technique required that everyone in the group offer at least one solution to handling a maladaptive eating problem, regardless of how ridiculous the alternative provided might have been. A solution was decided upon, and a strategy of dealing with the problem behavior was implemented.

The final week was used to gather post-treatment data on weight loss, means-end problem solving ability, and Locus of Control.

The External Control (EC) Group Procedure

The EC group met for only one hour each week as opposed to $1-1 / 2$ hours alloted for the separate CRT group.

In week three the EC group reviewed the food intake format to prevent potential error in recording of eating behavior. Subjects were asked to initiate the five cue elimination techniques earlier stated in the CRT procedure. 
Pavlovian principles were emphasized, but no mention of moods in relation of eating was broached. Relaxation exercises were not provided for the EC group as they were for the CRT group. In week four stimulus control techniques were again reviewed, and the step-by-step rationale of putting one's fork down was explained to the group. Any problems of application of these techniques was discussed.

Throughout weeks five and six, subjects were taught to break down behavioral chains which perpetuated maladaptive eating. Only external environmental cues were dealt with in the behavioral chains, and questions concerning mood, cognitions, or feelings were eschewed with the following statement: "There is currently research studying the role of moods, feelings, and thinking in the obese, but we will not be dealing with them in this class." Subjects composed a list of seven enjoyable activities and three necessary activities which would substitute for eating contingent upon untimely hunger pangs. It was explained that hunger pangs last approximately 15 minutes. If the subject engaged in an alternate activity through this 15 minute hunger pang, she would forget about eating. Subjects in the EC group did not learn to use alternate activities for mood-related eating.

Concepts of pre-planning meals were emphasized and given as homework assignments in the seventh week. 
Lesson eight provided additional sources of cue elimination in the external environment. subjects were instructed in the same six cue elimination techniques recommended to the CRT group. They did not participate in any work on cognitive behavior.

The ninth week was devoted to energy expenditure as a necessary component of weight control. Enjoyable activities were listed and subjects were to record the number of minutes during the next week that they engaged in such activities. They were also asked to purchase a pedometer to obtain baseline activity levels.

The final week was used to gather post-treatment data on weight loss, Locus of Control, and means-end problem solving activity. 


\section{TABLE I}

Treatment Schedules*

\begin{tabular}{c|l|l}
\hline Week & $\begin{array}{l}\text { Cognitive Restructuring } \\
\text { Training (CRT) }\end{array}$ & $\begin{array}{l}\text { External Environmental } \\
\text { Control Group (EC) }\end{array}$ \\
\hline 1 & $\begin{array}{l}\text { Pre-treatment data, MEPS } \\
\text { LC, weight, food intake } \\
\text { forms provided. } \\
\text { Mood recorded. }\end{array}$ & $\begin{array}{l}\text { Pre-treatment data, MEPS, } \\
\text { LC, weight, food intake } \\
\text { forms provided. } \\
\text { Mood not recorded. }\end{array}$ \\
\hline 2 & $\begin{array}{l}\text { I200 calorie eating } \\
\text { program initiated, } \\
\text { nutritional information } \\
\text { presented, importance of } \\
\text { recording stressed }\end{array}$ & $\begin{array}{l}\text { l200 calorie eating } \\
\text { program initiated, } \\
\text { nutritional information } \\
\text { presented, importance of } \\
\text { recording stressed }\end{array}$ \\
\hline 3 & $\begin{array}{l}\text { Initiated five cue } \\
\text { elimination techniques. } \\
\text { Relaxation training. } \\
\text { Taught to use relaxation } \\
\text { as a substitute for } \\
\text { eating due to fatigue or } \\
\text { stress. }\end{array}$ & $\begin{array}{l}\text { Initiated five cue } \\
\text { elimination techniques. }\end{array}$ \\
\hline 4 & $\begin{array}{l}\text { Review cue elimination. } \\
\text { Pinpoint individual } \\
\text { patterns of external } \\
\text { cues. down between each } \\
\text { Forks down } \\
\text { bite. } \\
\text { Closely monitor moods; } \\
\text { practice relaxation. }\end{array}$ & $\begin{array}{l}\text { Review cue elimination. } \\
\text { Pinpoint individual } \\
\text { patterns of external } \\
\text { cues. } \\
\text { Forks down between each } \\
\text { bite. }\end{array}$ \\
$\begin{array}{l}\text { Behavioral chains } \\
\text { external and internal } \\
\text { chained events } \\
\text { Seven enjoyable activi- } \\
\text { ties to substitute for } \\
\text { mood related eating. } \\
\text { Record fork down ratio. } \\
\text { Reward self for habits } \\
\text { not weight. }\end{array}$ & $\begin{array}{l}\text { Behavior chains with } \\
\text { attention only given to } \\
\text { external events. }\end{array}$ \\
\hline
\end{tabular}




\begin{tabular}{c|l|l}
\hline Week & $\begin{array}{l}\text { Cognitive Restructuring } \\
\text { Training (CRT) }\end{array}$ & $\begin{array}{l}\text { External Environmental } \\
\text { Control Group (EC) }\end{array}$ \\
\hline 6 & $\begin{array}{l}\text { As week five but insti- } \\
\text { gate three necessary } \\
\text { activities to substitute }\end{array}$ & $\begin{array}{l}\text { Substitute enjoyable and } \\
\text { necessary activities for } \\
\text { hunger pangs. }\end{array}$ \\
\hline 7 & $\begin{array}{l}\text { Preplanning meals. } \\
\text { Positive covert imagery } \\
\text { training. } \\
\text { Role playing mental } \\
\text { rehearsals. } \\
\text { Positive cognitive } \\
\text { rewards. }\end{array}$ & Preplanning meals. \\
\hline 8 & $\begin{array}{l}\text { Additional cue elimin- } \\
\text { ation techniques. } \\
\text { Review of cognitions } \\
\text { each day re: eating. } \\
\text { Counter negative } \\
\text { thoughts, reward } \\
\text { positive thoughts. }\end{array}$ & $\begin{array}{l}\text { Additional cue elimin- } \\
\text { ation techniques. }\end{array}$ \\
\hline 9 & $\begin{array}{l}\text { Energy expenditure } \\
\text { program. } \\
\text { Positive and negative } \\
\text { aspects of exercise. } \\
\text { Counter negative } \\
\text { thoughts pertaining to } \\
\text { exercise; reward } \\
\text { positive thoughts } \\
\text { pertaining to exercise. } \\
\text { Brainstorming session. }\end{array}$ & $\begin{array}{l}\text { Energy expenditure } \\
\text { program. }\end{array}$ \\
\hline 10 & $\begin{array}{l}\text { Post-treatment data. } \\
\text { Post-treatment data. }\end{array}$ \\
\hline
\end{tabular}


RESULTS

\section{Weight Loss}

In the cognitive restructuring (CRT) group, of the ten subjects who began the study, six completed the ten weeks. The four who dropped out of the program are not included in the following calculations. The mean weight loss of the six subjects in the CRT group was 8.29 pounds with a standard deviation of 5.20. Table. II, Appendix E, indicates weight changes in the CRT group.. Ideal weights were obtained from Hershman (1977) according to height and wrist measurements.

In the External Control (EC) group, six of eleven completed the entire weight loss program. Five were dropped from the study as they either missed two or more sessions or did not provide post-treatment data. Only the six who finished the ten weeks are included in the calculations. The mean weight change for the EC group was 6.0 pounds with a standard deviation of 7.77 pounds. Table III, Appendix E, provides the weight change information of the EC group.

of the ten Control group members, six provided full information. Ten were prompted via phone calls that informed them that they were entitled to the free weight loss program. However, four had lost interest. The mean 
weight change demonstrated a gain of 2.33 pounds. Table IV, Appendix E, shows the Control group weight change.

A one-way analysis of weight change (in pounds) revealed that there were significant differences in the effectiveness of the three treatment groups $(F=5.72$, $\mathrm{p}<.01)$. (See Table V, Appendix E.) Three planned comparisons were then performed to examine the hypothesized group differences in weight change. The results of these planned comparisons supported two of the three predictions. Both $\mathrm{CRT}$ and $\mathrm{EC}$ resulted in significantly greater weight loss than did the control condition $(t<15)=3.21, p<.005$ and $t(15)=2.52$, $\mathrm{p}<.025$, respectively). However, CRT did not reduce weight significantly more than EC $\left(t_{(15)}=.69\right)$.

While these three planned comparisons are not independent and also exceed the two degrees of freedom (the number of treatments minus one) normally allowed, they do permit an examination of the hypothesized effects of the treatments. Winer (1962) has indicated that

In practice the comparisons that are constructed are those having some meaning in terms of the experimental variables; whether these comparisons are orthogonal or not makes little or no difference (p. 175).

\section{Locus of Control}

The locus of control scores are presented in Appendix E, Table VII. An analysis of variance was 
performed to ascertain whether pre-treatment differences between the groups existed on the locus of control dependent variable (see Appendix E, Table VI). The results showed no significant difference in pre-treatment locus of control scores $F(2,15)=1.27)$.

In order to determine the effects of treatment on locus of control scores, pre-treatment and post-treatment measures were necessary. Table VII in Appendix E provides such information.

Since repeated measures on the data were obtained for all subjects, correlated t-tests were employed to determine whether significant changes in perceived locus of control had occurred for each of the three groups. In the CRT group, scores made a significant move toward internality when pre-treatment $(M=9.67)$ and posttreatment $(M=7.00)$ measures were compared $(t(5)=4.81$, $\mathrm{p}<.01)$. The EC group did not demonstrate significant changes $\left(M_{\text {pre }}=11.67, M_{\text {post }}=9.83 ; t(5)=1.50\right)$. Likewise, the control group made no significant shift toward internality or externality $\left(M_{\text {pre }}=9.83\right.$, $\left.M_{\text {post }}=9.50 ; t(5)=.94\right)$.

Means-Ends Problem Solving Ability

The MEPS scores are indicated in Table IX of Appendix E. An analysis of variance was carried out to determine if significant pre-treatment group differences 
existed (see Appendix E, Table VIII). The results indicated no significant difference in pre-treatment MEPS scores $\left(F_{2,15}=2.19\right)$.

In order to evaluate the effects of treatment on MEPS scores, differences in pre-treatment and posttreatment measures were examined. Table IX, Appendix E, provides the pertinent raw data.

Repeated measures $t$-tests were performed to find whether significant changes had occurred in performance on the MEPS for each of the three groups. In the CRT group, a significant increase in appropriate means occurred ( $\left.t_{5}=2.56, p<.05\right)$. When pre-treatment and post-treatment MEPS scores were compared in the EC group and in the control group, no significant change was apparent in either group $\left(t_{5}=1.31\right.$ and .28 , respectively.

It is noted that in all groups there was a high percentage of drop outs. The average drop out rate in weight control groups is 39 per cent (Ferguson, 1975). In this study the rate was approximately 42 per cent. For future screening of appropriate and/or motivated weight loss subjects or clients, it is useful to explore differences between subjects who completed the weight loss program and those who did not. Scores on Locus of Control and Means-Ends Problem Solving Device did not significantly differ between those who completed the 
treatment program and those who did not. However, the average weight of those who successfully completed the weight loss program was 21.5 pounds less than those who dropped out of the treatment or control groups. The mean weights of the completed groups vs. the group of people who did not follow through were 163.5 and 185 , respectively.

The variances and standard deviations are 540.53 and 23.25, respectively, for the completed group and 2126.86 and 46.12 , respectively, for the non-completes. To analyze whether these variances are significantly different, an $\mathrm{F}$ test for homogeneity of variance was conducted. The result indicated that the variance for the non-completes was significantly greater than the variance for the completes $(F(12,17)=3.93, p<.01)$. Therefore, homogeneity of variance cannot be assumed. Because of unequal and small sample sizes, the t-test which does not pool variances was employed. The t-test did not demonstrate significant differences in pre-test weight for the completed vs. the non-completed groups $(t(12 ; .05)=-1.56)$. In addition, for the 13 persons who did not finish the weight control program, the Pearson product-moment correlation between weight and locus of control was $r_{x y}=.20$, which was not statistically significant. 


\section{DISCUSSION}

The last decade has witnessed a marked change in views about the aspects of eating behaviors which cause, or are related to, obesity. The origins of such eating behavior had been assumed to result from some defective inner state, either metabolic or psychological. It was then concluded that the control of obesity lay in remedying that defect. Treatment generally consisted of a rigid, less than nourishing, low-calorie diet and/or an appetite-suppressant medication. No less common was the exhortation that the obese person should learn to exercise will-power and self-denial.

The development and the introduction of behavior modification as a treatment approach shifted the scientist's attention from defects within the individual to the environment around him. Behavior modification, through the measurement and quantification of objective criteria, was well suited to analyze how external factors exert their influence. Several studies attempt to elucidate which of the many behavioral techniques are the most effective.

With the introduction of cognitive behaviorism, an about face from strict Watsonian behaviorism, the sphere of cognitive behavior became available to researchers 
interested in the treatment of obesity. The empirical notion of quantifying and creating new cognitive behaviors lent itself to additional treatment modalities. With research continually verifying that the obese are more sensitive to external stimuli than physiological cues and more sensitive to external stimuli than their normal weight counterparts, this researcher was interested to find what changes in obesity, if any, would occur with known cognitive training techniques.

\section{Findings for the CRT Group.}

The proposed hypothesis was that the addition of a cognitive training program to a strictly external weight control program would be more effective in promoting weight loss than a treatment focusing on external factors alone. The Cognitive Restructuring Group was given techniques to enhance the individual's sensitivity to, and control of, cognitive, internal stimuli. The External Control group received no such technique. In addition, it was further hypothesized that cognitive training would result in significantly greater changes than external treatment on locus of control scores and the means-ends problem solving device. The data comparing mean weight losses of the Cognitive Restructuring and External Control groups did not support the hypothesis that the Cognitive Restructuring treatment modality would elicit a significantly greater 
mean weight loss than the External Control approach. Although statistical significance was not reached when comparing the effectiveness of the two approaches, the Cognitive Restructuring Group did yield a mean weight loss of 2.29 pounds more than the average weight loss of the External Control Group. Planned comparisons indicated that the Cognitive Restructuring Group achieved significantly greater weight loss than the control group receiving no treatment whatsoever. Repeated measures on pre-treatment and post-treatment data demonstrated that the group receiving Cognitive Restructuring training made statistically significant gains in MEPS scores and a significant shift toward internality in locus of control scores.

It must be emphasized that these conclusions are drawn from a small data base. Therefore, the comments are made from a conservative viewpoint, and the results are suggestive rather than conclusive.

Findings for the EC Group

The second hypothesis of this study was that external training is significantly more effective than no treatment as reflected by weight reduction, locus of control scores, and MEPS gains. The data comparing mean weight losses of the External Control and Control groups supported the hypothesis that the External Control 
treatment approach would produce significantly greater average weight loss than the control group receiving no treatment. In fact, individuals in the control group gained an average of 2.33 pounds from the initiation of the study to the time of its completion.

CRT and Success in Therapy

It appears that the Cognitive Restructuring group exceeds the control in affecting change in: 1) perceived internalization of locus of control, 2) weight reduction and, 3) problem solving ability. Although the Cognitive Restructuring group did not achieve significantly greater weight reduction than the External group, it did average 2.29 pounds greater weight loss. Furthermore, the Cognitive Restructuring group was the only group to have significant post-treatment effects in locus of control scores and Means-Ends Problem Solving. This success in therapy supports findings of Pierce (1970), who showed that such success is related to client internalization behavior. This raises the chicken or the egg question of which comes first. Does internalization of perceived locus of control produce greater therapeutic success, or does success breed internalization? As stated above, there was no significant correlation between locus of control and weight, nor did those who successfully completed treatment differ significantly from subjects dropping out of the 
weight control program. The question of which precedes the other remains rhetorical. However, the relationship between increased internalization and Cognitive Restructuring training does exist.

one advantage of a Cognitive Restructuring program over strictly external weight control programs is that it teaches the individual that she/he has the ability to monitor and modify his/her thoughts which influence inappropriate eating behaviors. Subjects in the study reported that cognitive exercises enhanced their ability to generate alternative ways to deal with difficult eating situations. A wider range of techniques were at hand to handle mood related eating. Although information was not specifically asked as to whether the cognitive exercises were generalized to other areas of their lives, the significant post-treatment MEPS scores indicate an increased ability to generate means to an end goal. A goal of both treatment groups was to train the subjects in self-management of their consumption and energy expenditure, in order that they will have techniques and skills to use on an ongoing, post-treatment basis.

Anecdotal Findings and the Future of CRT in Weight Control

Techniques used in both treatment groups are highly conducive to group situations. In the literature review there was not one study that indicated enhanced weight 
reduction on an individual counseling basis. However, in this study the average weight of drop outs exceeded the three completed groups by 21.5 pounds. This leads one to speculate that those who deviate inordinately in weight may shy away from group situations. It has been an observation of this writer in clinical cases that excessively obese clients are often embarrassed to socialize or be in view of others of lesser weight. Consequently, they shy away from group involvement.

As in many studies throughout the literature review, the experimental groups demonstrated a wide within group variability in weight reduction. Further research is necessary to determine and promote individual effectiveness within weight control groups. The Cognitive Restructuring group ranged in weight reduction from .75 pounds to 14 pounds with a standard deviation of 5.20 pounds. The range in the External Control group was from a gain of 4 pounds to a loss of 14 pounds. The variance was greater for the External Control group, the standard deviation being 7.70 pounds. However, when tested for homogeneity of variance, this difference in variance did not reach statistical significance $(F(5,5)=2.19)$. The decreased variability in the CRT group suggests a higher predictive validity of weight loss within that group.

An interesting event occurred at the termination of the experimental groups. Three of the six External Control 
group members had left notes of appreciation, two of which were accompanied by unsolicited monetary remuneration. None of the Cognitive Restructuring group members behaved in this fashion. The experimenter offers no explanation for this, but only the speculation that the External Control group might have better learned reinforcement principles.

The study was designed to assess the effectiveness of the two treatment groups when compared with each other and with a control group. The relative effectiveness of the external/cognitive stimulus dimensions was not differentiated in the two experimental groups when compared to each other. There may be other variables within the experimental procedures which explain their comparative effectivenss. Of greater importance is the maintenance of the weight loss of both experimental groups. A follow-up at six-month intervals for a period of three years would provide important information as to which treatment provided more long-lasting effects. The Cognitive Restructuring group would have a greater number of tools and would have been prepared in a wider variety of stimulus situations. Therefore, this writer hypothesizes that maintenance of weight loss would be higher among members of the Cognitive Restructuring group. A six-month follow up is scheduled for the two experimental groups. 


\section{BIBLIOGRAPHY}

Balch, Philip, and Ross, W. "Predicting success in weight reduction as a function of Locus of Control: A unidimensional and multidimensional approach." Journal of Consulting and Clinical Psychology 43(1) (1975):119.

Bandura, Albert. Principles of Behavior Modification. New York: Holt, Rinehart and Winston, 1969.

"Vicarious and self-reinforcement processes." In The Nature of Reinforcement, pp. 228-278. Edited by R. Glaser. New York: Academic Press, 1971.

Cautela, J. R. "Covert negative reinforcement." Journal of Behavior Therapy and Experimental Psychiatry $1(1970): 273-278$ (a).

- "Covert reinforcement." Behavior Therapy 1 $(1970): 33-50$ (b).

Davis, G. A. "Current status of research and theory in human problem solving." Psychological Bulletin 66 $(1966): 36-54$.

- Psychology of Human Problem Solving: Theory and Practice. New York: Basic Books, 1973.

de Charms, R. Personal Causation. New York: Academic Press, $19 \overline{68 .}$

D' Zurilla, T. J. and Goldfried, M. R. "Problem solving and behavior modification." Journal of Abnormal Psychology 78 (1971):107-126.

Ellis, Albert. Reason and Emotion in Psychotherapy. New York: Stuart, 1962.

Felton, G. S., and Biggs, B. E. "Teaching internalization behavior to collegiate low achievers; group psychotherapy." Psychotherapy: Theory, Research and Practice 9 (1972):281-283.

Ferguson, James M. Learning to Eat. Palo Alto, Calif.: Bull Publishing Co., 1975 . 
Gagne, R. M. "Problem solving." In Categories of Human Learning, pp. 293-317. Edited by A. W. Melton. New York: Academic Press, 1964.

Geller, Sanford, Keane, Schirer et al. "Delay of gratification, locus of control and eating patterns of obese and non-obese children." Paper presented at Association of the Advancement of Behavior Therapy Convention, Atlanta, December 1977.

Hershman, Jerome. Endocrine Pathophysiology: A Patient oriented Approach. London: Henry Kimpton, 1977.

Homme, L. E. "Perspectives in psychology: XXIV. Control of coverants, the operants of the mind." Psychological Record 15 (1965):501-511.

Horan, J. J., Baker, S. B., Hoffman, A. M., and Shute, R. E. "Weight loss through variations in the coverant control paradigm." Paper presented to the American Educational Research Foundation, Chicago, April 1974.

Horan, J. J. and Johnson R. G. "Coverant conditioning through a self-management application of the Premack principle: Its effect on weight reduction." Journal of Behavior Therapy and Experimental Psychiatry 2 (1971):243-249.

Jeffrey, C. B. "A comparison of the effects of the external control and self-control on the modification and maintenance of weight." Journal of Abnormal Psychology 83 (1974):404-410.

Kanfer, F. H. and Phillips, J. S. Learning Foundations of Behavior Therapy. New York: Wiley, 1970 .

Mahoney, M. J. "The self-management of covert behavior: A case study." Behavior Therapy 3 (1971):575-57.8.

Mahoney, M. J., and Mahoney K. Permanent Weight Control: A Total Solution to the Dieter's Dilemma. New York: W. W. Norton, 1976 .

Mahoney, Michael. Cognition and Behavior Modification. Cambridge, Mass.: Ballinger Pub. Co., 1974.

Manno, B. and Marston, A. R. "Weight reduction as a function of negative covert reinforcement vs. positive covert reinforcement." Behavior Research and Therapy 10 (1972) : 201-208. 
McFall, R. M. "The effects of self-monitoring on normal smoking behavior." Journal of Consulting and Clinical Psychology 35 (1970):135-142.

Meichenbaum, D. Cognitive Behavior Modification. Morristown, New Jersey: General Learning Press, 1974.

Mischel, W. "Toward a cognitive social learning reconceptualization of personality. Psychological Review 80 (1973):252-283.

Nisbett, R. E. "Taste, deprivation, and weight determinants of eating behavior." Journal of Personality and Social Psychology 10 (1968):107-116.

Pierce, R. M., Schauble, P. G., and Farkas, A. "Teaching internalization behavior to clients." Psychotherapy: Theory, Research, and Practice 7 (1970):217-220.

Platt, Jerome, Scura, W., and Hannon, J. "Problem-solving thinking of youthful incarcerated heroin addicts." Journal of Community Psychology 3(1) (1973):278-281.

Platt, Jerome, and Spivack, George. Manual for the MeansEnds Problem Solving Procedure (MEPS), A Measure of Interpersonal Cognitive Problem Solving Skill. Philadelphia, Penn.: Dept. of Mental Health Science, 1971 (revised 1975).

Premack, D. "Catching up with common sense or two sides of a generalization: Reinforcement and punishment." In The Nature of Reinforcement, pp. 121-150. Edited by R. Glaser. New York: Academic Press, 1971.

Rotter, J. B. Psychological Monographs 80 (1966) [1, whole no. 609].

- Social Learning and Clinical Psychology. Englewood Cliffs, New Jersey: Prentice-Hall, 1954.

Schachter, S. "Some extraordinary facts about obese humans and rats." American Psychologist 26(2) $(1971): 129-144$.

Sheerer, M. "Problem solving." Scientific American 208 (1963) : 118-128.

Spivak, George, and Spotts, Jules. "Adolescent symptomatology." American Journal of Mental Deficiency $72(1)$ (1967):74-95. 
Stuart, Richard, and Davis, Barbara. Slim Chance in a Fat World. Champaign, Illinois: Research Press, 1972.

Wilson, G. T. "Aversive control of maladaptive behavior." Paper presented at Pennsylvania State University, January 1974.

Winer, B. J. Statistical Principles in Experimental

Design. New York: McGraw-Hill, 1962. 
APPENDIX A

INFORMED CONSENT

I,

subject's name

, hereby agree to serve as

a subject in the research project on Weight Control

conducted by Lisa Buckmaster who is a graduate student at Portland State University and supervised by Dr. Pamela 0. Munter, Professor of Psychology, Portland State University.

I understand that the study involves attendance to each of ten weekly meetings, filling out confidential questionnaires, and weekly "weigh-ins."

I understand that possible risks to be associated with this study are:

1. alterations in diet which could affect my health particularly if I am hypertensive, diabetic, etc. The diet used in this research is well balanced and nutritionally sound. However, if there is a question regarding the appropriateness of this diet for my health problem, I should consult with a physician prior to participating in this study.

It has been explained to me that the purpose of the study is to learn effective weight control techniques. I may not receive any direct benefit from participating in this study, but my participation may help to increase knowledge which may benefit others in the future. 
Lisa Buckmaster has offered to answer any questions I may have about the study and what is expected of me in the study.

I understand that I am free to withdraw from participation in this study at any time without jeopardizing my relationship with Portland State University.

My name, and other personal information about me, is to be kept in strict confidentiality. Information about my experience may be included in the research report only when total anonymity is guaranteed.

I have read and understand the foregoing information.

SIGNATURE OF SUBJECT AGE DATE

SIGNATURE OF GUARDIAN, IF UNDER 18

AGE DATE

Release obtained by

If you experience problems that are the result of your participation in this study, please contact Richard Streeter, Office of Graduate Studies and Research, 105 Neuberger Hall, Portland State University, 229-3423. 


\section{APPENDIX B \\ LOCUS OF CONTROL}

This is a questionnaire to find out how certain important situations in people's lives affect them.

Please answer the following questions the way you

feel. There are no right or wrong answers. Circle either "yes" or "no" on the answer sheet according to your first feeling. Don't take a lot of time answering any one question, answer them all.

If you feel like answering both yes and no to the same question, then answer "yes" if it's a little more yes than no, and answer "no" if it's a little more no than yes.

1. Do you believe that most problems will solve themselves if you just don't fool with them?

2. Do you believe that you can stop yourself from catching cold?

3. Are some people just born lucky?

4. Most of the time do you feel that getting good grades meant a great deal to you?

5. Are you often blamed for things that just aren't your fault? 
6. Do you believe that if somebody studies hard enough he or she can pass any subject?

7. Do you feel that most of the time it doesn't pay to try hard because things never turn out right anyway?

8. Do you feel that if things start out well in the morning that it's going to be a good day no matter what you do?

9. Do you feel that most of the time parents listen to what their children have to say?

10. Do you believe that wishing can make good things happen?

11. When you get punished does it usually seem it's for no reason at all?

12. Most of the time do you find it hard to change a friend's (mind) opinion?

13. Do you think that cheering more than luck helps a team to win?

14. Did you feel that it was nearly impossible to change your parent's mind about anything?

15. Do you believe that parents should allow children to make most of their own decisions?

16. Do you feel that when you do something wrong there's very little you can do to make it right?

17. Do you believe that most people are just born good at sports? 
18. Are most of the other people your age stronger than you are?

19. Do you feel that one of the best ways to handle most problems is just to not think about them?

20. Do you feel. that you have a lot of choice in deciding whom your friends are?

21. If you find a four leaf clover, do you believe that it might bring you good luck?

22. Did you often feel that whether or not you did your homework had much to do with what kind of grades you got?

23. Do you feel that when a person your age is angry at you, there's little you can do to stop him or her?

24. Have you ever had a good luck charm?

25. Do you believe that whether or not people like you depends on how you act?

26. Did your parents usually help you if you asked them to?

27. Have you felt that when people were angry with you it was usually for no reason at all?

28. Most of the time, do you feel that you can change what might happen tomorrow by what you do today?

29. Do you believe that when bad things are going to happen they just are going to happen no matter what you try to do to stop them?

30. Do you think that people can get their own way if they just keep trying? 
31. Most of the time do you find it useless to try to get your own way at home?

32. Do you feel that when good things happen they happen because of hard work?

33. Do you feel that when somebody your age wants to be your enemy there's little you can do to change matters?

34. Do you feel that it's easy to get friends to do what you want them to?

35. Do you usually feel that you have little to say about what you get to eat at home?

36. Do you feel that when someone doesn't like you there's little you can do about it?

37. Did you usually feel that it was almost useless to try in school because other children were just plain smarter than you are?

38. Are you the kind of person who believes that planning ahead makes things turn out better?

39. Most of the time, do you feel that you have little to say about what your family decides to do?

40. Do you think it's better to be smart than to be lucky? 


\author{
APPENDIX C \\ MEANS-ENDS STORIES
}

\title{
Instructions
}

In this procedure we are interested in your imagination. You are to make up some stories. For each story you will be given the beginning of the story and how the story ends. Your job is to make up a story that connects the beginning that is given you with the ending given you. In other words, you will make up the middle of the story.

Write at least one paragraph for each story.

1. Ms. A was listening to the people speak at a meeting. about how to make things better in her neighborhood. She wanted to say something important and have a chance to be a leader too. The story ends with her being elected leader and presenting a speech. You begin the story at the meeting where she wanted to have a chance to be a leader.

2. H. loved her boyfriend very much, but they had many arguments. One day he left her. H. wanted things to be better. The story ends with everything fine between her and her boyfriend. You begin the story 
with her boyfriend leaving her after an argument.

3. Ms. P. came home after shopping and found that she had lost her new watch. She was very upset about it. The story ends with Ms. P. finding her watch and feeling good about it. You begin the story where Ms. P. found that she had lost her watch.

4. Ms. C. had just moved in that day and didn't know anyone. Ms. C. wanted to have friends in the neighborhood. The story ends with Ms. C. having many good friends and feeling at home in the neighborhood. You begin the story with Ms. C. in her room immediately after arriving in the neighborhood.

5. During the Nazi occupation a woman's husband and children were viciously tortured and killed by an SS trooper, and the woman swore revenge. The story begins one day after the war, when the woman enters a restaurant and sees the ex-ss trooper. The story ends with the woman killing the ss trooper. You begin when she sees the ss trooper.

6. One day Lynn saw a handsome man she had never seen before while eating in a restaurant. She was immediately attracted to him. The story ends when they get married. You begin when Lynn first notices 
the man in the restaurant.

7. Bobbi needed money badly. The story begins one day when she notices a valuable diamond in a shop window. Bobbi decides to steal it. The story ends when she succeeds in stealing the diamond. You begin when she sees the diamond.

8. Joan noticed that her friends seemed to be avoiding her. Joan wanted to have friends and be liked. The story ends when Joan's friends like her again. You begin when she first notices her friends avoiding her.

9. One day Ginny was standing around with some other people when one of them said something very nasty to Ginny. Ginny got very mad. Ginny got so mad she decided to get even with the other person. The story ends with Ginny happy because she got even. You begin the story when Ginny decided to get even.

10. Anne is having trouble getting along with the supervisor on her job. Anne is very unhappy about this. The story ends with Anne's supervisor liking her. You begin the story where Anne isn't getting along with her supervisor.

$I_{\text {The MEPS }}$ can be either self- or experimenteradministered. The educational background, motivational 
level, and general intellectual competence of the subject should be taken into account in deciding which method to use. The MEPS has always been experimenter administered when given to psychiatric patients and educationally limited controls. Both self- and experimenter-administered forms have been used with normal subjects and no significant difference in mean story length or scores have been found as a result of the two methods of administration. 
APPENDIX D

DAILY FOOD INTAKE

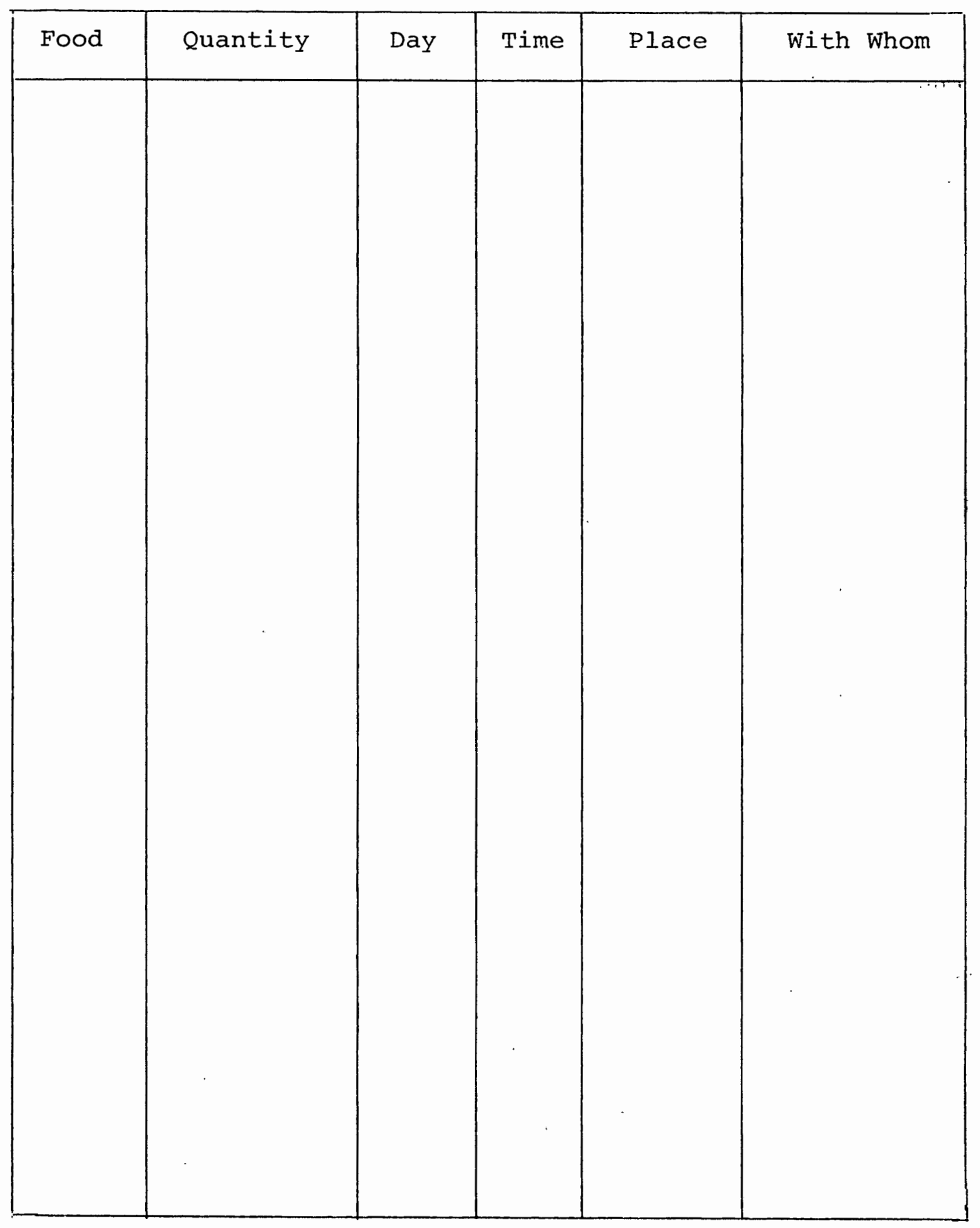


56

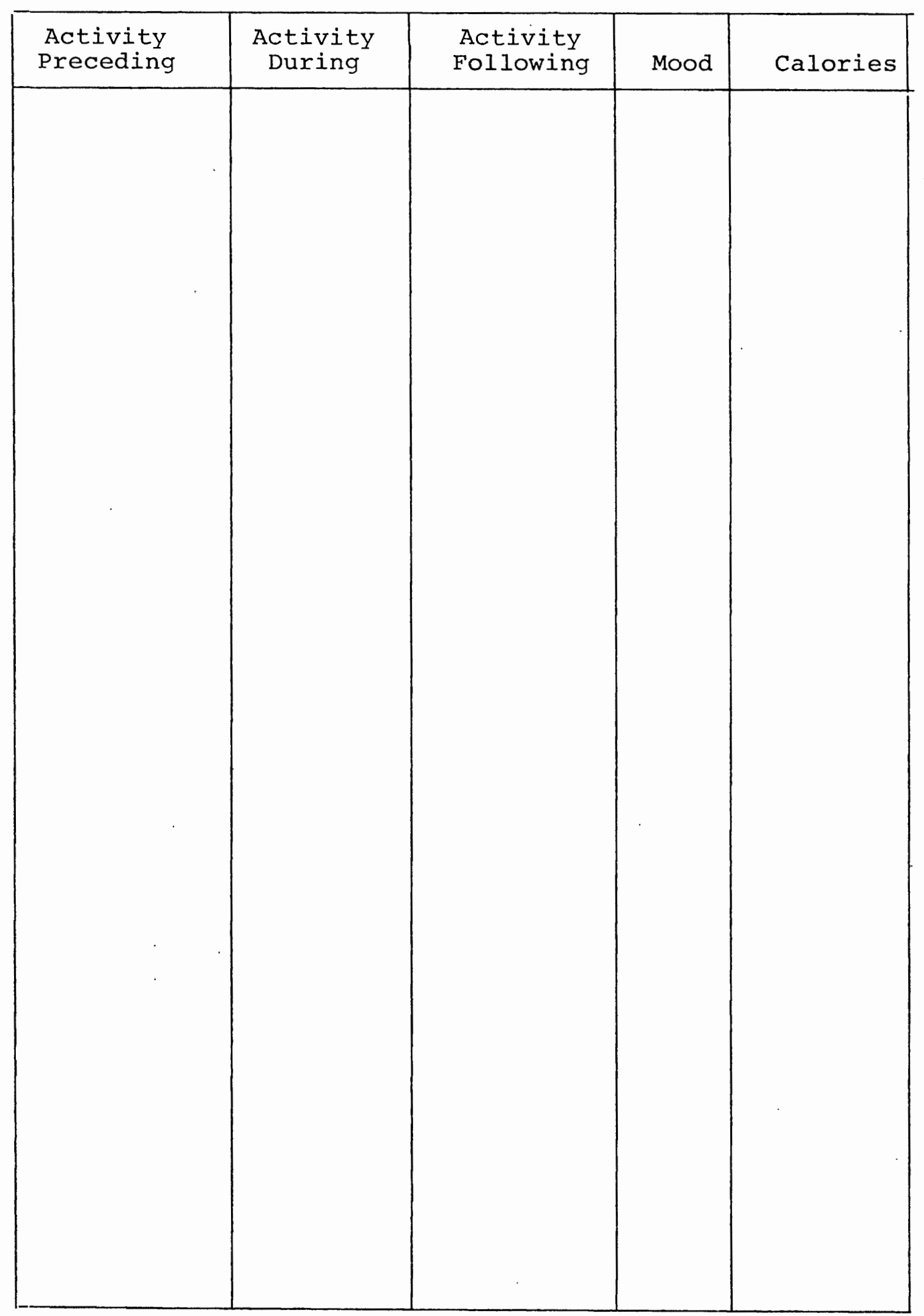


APPENDIX E

TABLES 
TABLE II

COGNITIVE RESTRUCTURING SUBJECTS'

WEIGHT CHANGE IN POUNDS

\begin{tabular}{ccccc} 
Subject & $\begin{array}{c}\text { Pre-Treatment } \\
\text { Weight }\end{array}$ & $\begin{array}{c}\text { Post-Treatment } \\
\text { Weight }\end{array}$ & $\begin{array}{c}\text { Ideal } \\
\text { Weight }\end{array}$ & $\begin{array}{c}\text { Weight } \\
\text { Change }\end{array}$ \\
\hline$S_{11}$ & 134.25 & 126 & 120 & -8.25 \\
$S_{12}$ & 168.75 & 168 & 137.5 & -.75 \\
$S_{13}$ & 159.75 & 156 & 120 & -3.75 \\
$S_{14}$ & 135.0 & 125 & 120 & -10.0 \\
$S_{15}$ & 155.0 & 141 & 115 & -14.0 \\
$S_{16}$ & 144.0 & 131 & 110 & -13.0 \\
\hline
\end{tabular}

$a_{M}=-8.29$ lbs. $\quad S D=5.20$ lbs. 
TABLE III

EXTERNAL CONTROL SUBJECTS'

WEIGHT CHANGE IN POUNDS

\begin{tabular}{ccccr} 
Subject & $\begin{array}{c}\text { Pre-Treatment } \\
\text { Weight }\end{array}$ & $\begin{array}{c}\text { Post-Treatment } \\
\text { Weight }\end{array}$ & $\begin{array}{c}\text { Ideal } \\
\text { Weight }\end{array}$ & $\begin{array}{r}\text { Weight } \\
\text { Change }\end{array}$ \\
\hline$S_{21}$ & 188 & 190 & 115 & 2 \\
$S_{22}$ & 188 & 183 & 135 & -5 \\
$S_{23}$ & 168 & 157 & 120 & -9 \\
$S_{24}$ & 158 & 162 & 125 & 4 \\
$S_{25}$ & 212 & 198 & 143 & -14 \\
$S_{26}$ & 134 & 120 & 120 & -14 \\
\hline
\end{tabular}

$$
a_{M}=-6.0 \text { lbs. } \quad S D=7.77 \text { lbs. }
$$


TABLE IV

CONTROL SUBJECTS '

WEIGHT CHANGES IN POUNDS

\begin{tabular}{ccccc} 
Subject & $\begin{array}{c}\text { Pre-Study } \\
\text { Weight }\end{array}$ & $\begin{array}{c}\text { Post-Study } \\
\text { Weight }\end{array}$ & $\begin{array}{c}\text { Ideal } \\
\text { Weight }\end{array}$ & $\begin{array}{c}\text { Weight } \\
\text { Change }\end{array}$ \\
\hline $\mathrm{S}_{31}$ & 166 & 166 & 110 & 0 \\
$\mathrm{~S}_{32}$ & 157 & 162 & 120 & 5 \\
$\mathrm{~S}_{33}$ & 210 & 208 & 140 & -2 \\
$\mathrm{~S}_{34}$ & 146 & 147 & 109 & 1 \\
$\mathrm{~S}_{35}$ & 161 & 164 & 115 & 3 \\
$\mathrm{~S}_{36}$ & 158 & 165 & 125 & 7 \\
\hline
\end{tabular}

$a_{M}=2.23 \quad S D=3.33$ 
TABLE V

ANALYSIS OF VARIANCE SUMMARY TABLE

OF WEIGHT CHANGE

\begin{tabular}{|l|c|c|c|c|}
\hline Source of Variation & Sum of Squares & d.f. & Mean Square & F \\
\hline Between Groups & 375.18 & 2 & 187.59 & 5.72 \\
Within Groups & 491.82 & 15 & 32.79 & \\
\hline Total & 867.00 & 17 & & \\
\hline
\end{tabular}


TABLE VI

ANALYSIS OF VARIANCE SUMMARY TABLE

LOCUS OF CONTROL: PRE-TREATMENT SCORES

\begin{tabular}{|l|c|c|c|c|}
\hline Source of Variation & Sum of Squares & d.f. & Mean Square & $F$ \\
\hline Between Groups & 25.44 & 2 & 12.72 & 1.27 \\
Within Groups & 241.50 & 15 & 16.10 & \\
\hline Total & 266.94 & 17 & & \\
\hline
\end{tabular}


TABLE VII

PRE-TREATMENT AND POST-TREATMENT

SCORES ON LOCUS OF CONTROL*

Cognitive Restructuring Group (CRT)

\begin{tabular}{c|c|c} 
Subject & Pre-Treatment & Post-Treatment \\
\hline$S_{11}$ & 8 & 5 \\
$S_{12}$ & 12 & 9 \\
$S_{13}$ & 9 & 8 \\
$S_{14}$ & 17 & 13 \\
$S_{15}$ & 10 & 6 \\
$S_{16}$ & 2 & 1 \\
& $M=9.67$ & $M=7.00$ \\
& $S D=4.93$ & $S D=4.05$ \\
\hline
\end{tabular}

Lower scores indicate more internalization in locus of control. The lower the score, the more internal, or the more control one feels he/she has in the environment.

External Control Group (EC)

\begin{tabular}{c|c|c} 
Subject & Pre-Treatment & Post-Treatment \\
\hline$S_{21}$ & 13 & 11 \\
$S_{22}$ & 11 & 10 \\
$S_{23}$ & 13 & 8 \\
$S_{24}$ & 11 & 14 \\
$S_{25}$ & 17 & 12 \\
$S_{26}$ & 5 & 4 \\
& $M=11.67$ & $M=9.83$ \\
& $S D=3.93$ & $S D=3.49$ \\
\hline
\end{tabular}




\begin{tabular}{c|c|c} 
Subject & $\begin{array}{c}\text { Control Group } \\
\text { Pre-Treatment }\end{array}$ \\
\hline $\mathrm{S}_{31}$ & 6 & 8 \\
$\mathrm{~S}_{32}$ & 13 & 15 \\
$\mathrm{~S}_{33}$ & 11 & 10 \\
$\mathrm{~S}_{34}$ & 6 & 7 \\
$\mathrm{~S}_{35}$ & 7 & 5 \\
$\mathrm{~S}_{36}$ & 10 & 12 \\
& 8.83 & $\mathrm{M}=9.50$ \\
& $\mathrm{M}=2.93$ & $\mathrm{SD}=3.62$ \\
\hline
\end{tabular}


TABLE VIII

ANALYSIS OF VARIANCE SUMMARY TABLE

MEPS PRE-TREATMENT

\begin{tabular}{|l|c|c|c|c|}
\hline Source of Variation & Sum of Squares & d.f. & Mean Square & F \\
\hline Between Groups & 4.3 & 2 & 2.15 & 2.19 \\
Within Groups & 14.7 & 15 & .98 & \\
\hline Total & 19.0 & 17 & & \\
\hline
\end{tabular}


TABLE IX

MEPS PRE-TREATMENT AND POST-TREATMENT SCORES* Cognitive Restructuring Group (CRT)

\begin{tabular}{l|r|r} 
Subject & Pre-Treatment & Post-Treatment \\
\hline$S_{11}$ & 2.0 & 2.4 \\
$S_{12}$ & 2.7 & 3.6 \\
$S_{13}$ & 1.8 & 2.0 \\
$S_{14}$ & 2.9 & 2.9 \\
$S_{15}$ & 1.6 & 1.8 \\
$S_{16}$ & 2.5 & 2.8 \\
& $M=2.25$ & $M=2.58$ \\
& $S D=524$ & $S D=.66$ \\
\hline
\end{tabular}

${ }^{*}$ Higher MEPS scores indicate increased ability in problem solving as defined earlier in text.

External Control Group (EC)

\begin{tabular}{c|c|c} 
Subject & Pre-Treatment & Post-Treatment \\
\hline $\mathrm{S}_{21}$ & 3.5 & 2.8 \\
$\mathrm{~S}_{22}$ & 1.2 & 1.3 \\
$\mathrm{~S}_{23}$ & 1.8 & 2.6 \\
$\mathrm{~S}_{24}$ & .8 & 1.0 \\
$\mathrm{~S}_{25}$ & .8 & 1.3 \\
$\mathrm{~S}_{26}$ & .6 & 1.8 \\
& $\mathrm{M}=1.45$ & $\mathrm{M}=1.47$ \\
& $\mathrm{SD}=1.09$ & $\mathrm{SD}=1.36$ \\
\hline
\end{tabular}


Control Group

\begin{tabular}{c|c|c} 
Subject & Pre-Treatment & Post-Treatment \\
\hline $\mathrm{S}_{31}$ & 1.5 & 1.5 \\
$\mathrm{~S}_{32}$ & 1.2 & 1.0 \\
$\mathrm{~S}_{33}$ & 2.0 & 2.3 \\
$\mathrm{~S}_{34}$ & .9 & .8 \\
$\mathrm{~S}_{35}$ & 3.0 & 2.9 \\
$\mathrm{~S}_{36}$ & 1.2 & 1.4 \\
& $\mathrm{M}=1.63$ & $\mathrm{M}=1.65$ \\
& $\mathrm{SD}=.77$ & $\mathrm{SD}=.80$ \\
\hline
\end{tabular}

